\title{
Rendimento, composição química e atividade antilisterial de óleos essenciais de espécies de Cymbopogon
}

\author{
OLIVEIRA, M.M.M. ${ }^{1 *}$; BRUGNERA, D.F. ${ }^{1}$; CARDOSO, M.G. ${ }^{2}$; GUIMARÃES, L.G.L. ${ }^{2}$ PICCOLI, R.H. ${ }^{1}$ \\ ${ }^{1}$ Departamento de Ciência dos Alimentos, ${ }^{2}$ Departamento de Química, Universidade Federal de Lavras, CEP: \\ 37200-000, Lavras-Brasil*mmacielmattos@yahoo.com.br
}

\begin{abstract}
RESUMO: Objetivou-se determinar o rendimento, a composição química e avaliar a atividade antilisterial dos óleos essenciais de Cymbopogon citratus (DC.) Stapf. (capim-limão) e Cymbopogon nardus (L.) Rendle (capim-citronela), puros e em combinação. A obtenção dos óleos essenciais foi realizada a partir de folhas frescas, empregando-se a técnica de hidrodestilação e utilizandose aparelho de Clevenger modificado. Os rendimentos foram calculados a partir da massa obtida na extração e da umidade do material vegetal. A análise qualitativa foi realizada por cromatografia em fase gasosa acoplada à espectrometria de massas e a avaliação dos teores dos constituintes químicos por cromatografia em fase gasosa com detector de ionização de chamas. $O$ efeito bacteriostático de diferentes concentrações dos óleos essenciais, puros e em combinação, foi determinado pela técnica de difusão em ágar. As concentrações mínimas inibitórias (CMIs) foram utilizadas na determinação do tempo de ação bactericida. O rendimento, em base seca, foi de $1,39 \%$ (v/p) para o óleo essencial de $C$. citratus e de 2,27\% (v/p) para o óleo essencial de $C$. nardus. Geranial e neral foram os constituintes majoritários do óleo essencial de $C$. citratus, enquanto, para C. nardus, foram citronelal, geraniol e citronelol. A maioria das concentrações utilizadas mostrou-se efetiva contra Listeria monocytogenes e observaram-se efeitos bactericidas nas CMls. Óleos essenciais de $C$. citratus e $C$. nardus, puros e em combinação, constituem novas alternativas de antibacterianos naturais a serem utilizados no controle de $L$. monocytogenes na indústria de alimentos.
\end{abstract}

Palavras-chave: Cymbopogon citratus, Cymbopogon nardus, óleos essenciais, atividade antibacteriana, Listeria monocytogenes

ABSTRACT: Yield, chemical composition and antilisterial activity of essential oils from Cymbopogon species. The aim of this study was to determine the yield and the chemical composition of essential oils from Cymbopogon citratus (DC.) Stapf. (lemongrass) and Cymbopogon nardus (L.) Rendle (citronella), and to evaluate their antilisterial activity when pure and combined. The essential oils were obtained from fresh leaves through hydrodistillation by using a modified Clevenger-type device. Yield was calculated based on the extracted mass and the plant humidity. The qualitative analysis was done by gas chromatography-mass spectrometry and the levels of the chemical components were detected by gas chromatography with flame ionization detector. The bacteriostatic effect of different concentrations of pure and combined essential oils was determined by the agar diffusion technique. Minimum inhibitory concentrations (MICs) were used to determine the time of bactericidal action. The yield was $1.39 \%\left(\mathrm{v} \mathrm{w}^{-1} \mathrm{dry}\right.$ basis) for $C$. citratus essential oil and $2.27 \%\left(\mathrm{v} \mathrm{w}^{-1}\right)$ for $C$. nardus essential oil. Geranial and neral were the major components of $C$. citratus essential oil, while citronellal, geraniol and citronellol were predominant in $C$. nardus oil. Most of the used concentrations were efficient against Listeria monocytogenes and bactericidal effects were observed for the MICs. Essential oils of $C$. citratus and $C$. nardus, pure and combined, constitute new alternatives of natural antibacterials for the control of $L$. monocytogenes in the food industry.

Key words: Cymbopogon citratus, Cymbopogon nardus, essential oils, antibacterial activity, Listeria monocytogenes

Recebido para publicação em 07/03/2009

Aceito para publicação em 18/10/2010

Rev. Bras. PI. Med., Botucatu, v.13, n.1, p.8-16, 2011. 


\section{INTRODUÇÃO}

A flora brasileira é muito diversificada e rica (Giulietti et al., 2005). O gênero Cymbopogon possui mais de 100 espécies nos países tropicais, inclusive no Brasil, dentre as quais, aproximadamente 56 são aromáticas. A algumas delas deve-se dar atenção especial pelo grande uso na medicina popular e teor de óleo essencial com as mais diferentes finalidades, como uso terapêutico, cosmético ou em perfumaria (Lorenzi \& Matos, 2002). Dentro deste gênero encontram-se Cymbopogon citratus (DC.) Stapf. (capim-limão), originário da Índia, conhecido por fornecer óleo essencial rico em citral (Ming et al., 1996) e Cymbopogon nardus (L.) Rendle (capimcitronela), originário do Ceilão, conhecido pelo poder repelente do óleo essencial rico em citronelal (Castro \& Ramos, 2003).

Os óleos essenciais são originados do metabolismo secundário das plantas e possuem composição química complexa, destacando-se a presença de terpenos e fenilpropanóides. Constituem elementos voláteis contidos em muitos órgãos vegetais e estão relacionados com diversas funções necessárias à sobrevivência (Siani et al., 2000). Segundo Kelsey et al. (1984), as plantas sintetizam e emitem inúmeros compostos voláteis com a finalidade de defenderem-se ou de atrair os polinizadores. Por isso, os óleos essenciais são considerados fontes em potencial de substâncias biologicamente ativas, principalmente contra microrganismos, como bactérias, fungos filamentosos e leveduras.

Atualmente, crescente procura por plantas medicinais e aromáticas é observada em diversos países, devido à tendência dos consumidores em utilizarem, preferencialmente, produtos farmacêuticos ou alimentícios de origem natural (Martinazzo et al., 2007). Assim, tecnologias naturais de conservação vêm se tornando cada vez mais importantes em indústrias de alimentos e os óleos essenciais constituem alternativas à obtenção de produtos microbiologicamente seguros (Ultee et al., 1999).

A listeriose é doença transmitida por alimentos causada por Listeria monocytogenes. Apesar da baixa incidência, esta enfermidade possui elevada taxa de mortalidade, quando comparada às demais toxinfecções alimentares (Rocourt et al., 2000). A ampla distribuição deste patógeno com habilidade de crescimento em temperaturas de refrigeração e tolerância a certos conservantes utilizados na indústria de alimentos tem resultado em extensivos esforços no desenvolvimento de processos de controle do seu crescimento.

O estudo da atividade antibacteriana de óleos essenciais frente a $L$. monocytogenes tem sido realizado, principalmente, in vitro (Oussalah et al., 2007) e, recentemente, pela aplicação simultânea da bactéria e de óleos essenciais em produtos alimentícios (Cava et al., 2007; Solomakos et al., 2008). Uma alternativa, ainda mais recente, é a utilização de óleos essenciais como sanificantes no controle de biofilmes (Lebert et al., 2007; Chorianopoulos et al., 2008). A maioria dos trabalhos realizados tem alcançado excelentes resultados, demonstrando que o controle de $L$. monocytogenes por meio da utilização de óleos essenciais é uma linha de pesquisa relativamente nova e promissora.

A pesquisa com óleos essenciais que podem ser utilizados no controle de bactérias patogênicas na indústria de alimentos requer, como etapa inicial, o estudo da atividade antimicrobiana in vitro. Neste contexto, alguns fatores devem ser considerados e avaliados conjuntamente, como (i) rendimento de óleo essencial da espécie vegetal utilizada, importante do ponto de vista econômico; (ii) composição química do óleo essencial, que irá influenciar diretamente na atividade biológica; (iii) concentração do óleo essencial a ser utilizada; (iv) efeito bactericida e ou bacteriostático do óleo essencial, bem como o tempo necessário para que estes ocorram e (v) possível ação sinergística da combinação de óleos essenciais de espécies vegetais distintas.

Diante do exposto, face à importância do estudo de novas substâncias naturais capazes de controlar o crescimento e a presença de $L$. monocytogenes na indústria de alimentos, objetivouse, neste trabalho, determinar o rendimento e a composição química dos óleos essenciais de $C$. citratus e $C$. nardus, bem como avaliar a atividade antibacteriana dos mesmos, puros e em combinação.

\section{MATERIAL E MÉTODO}

\section{Materiais vegetais}

Foram utilizados $2.000 \mathrm{~g}$ de folhas frescas de Cymbopogon citratus (DC.) Stapf. (capim-limão) e Cymbopogon nardus (L.) Rendle (capim-citronela), coletadas no Horto de Plantas Medicinais da Universidade Federal de Lavras (UFLA). Acoleta foi realizada em janeiro de 2008, às 8 horas da manhã, em um dia com temperatura amena e sem precipitação pluviométrica. A cidade de Lavras localiza-se no sul do estado de Minas Gerais (Brasil), a latitude 21ำ14' S, longitude 4500' W Gr. e $918 \mathrm{~m}$ de altitude. De acordo com Dantas et al. (2007), o clima, segundo a classificação climática de Köppen, é Cwa, temperado chuvoso (mesotérmico), com inverno seco e verão chuvoso, subtropical, com inverno seco e temperatura do mês mais quente maior que $22^{\circ} \mathrm{C}$ (22,8드 em fevereiro).

\section{Determinação da umidade dos materiais vegetais}

Para a determinação da umidade dos materiais vegetais, $5 \mathrm{~g}$ de folhas frescas picadas foram 
imersas em $80 \mathrm{~mL}$ de ciclohexano $\left(\mathrm{C}_{6} \mathrm{H}_{12}\right)$ em balão de fundo redondo com capacidade de $250 \mathrm{~mL}$. Este foi acoplado a um condensador com coletor volumetricamente graduado. $\mathrm{O}$ aquecimento do balão foi realizado manta aquecedora, controlando-se a temperatura a, aproximadamente, $100^{\circ} \mathrm{C}$. Após 2,5 horas, o volume de água presente nas folhas foi quantificado. Aumidade foi calculada a partir do teor de água contido em $100 \mathrm{~g}$ da amostra (Pimentel et al., 2006).

\section{Extração dos óleos essenciais e determinação do rendimento}

O processo de extração dos óleos essenciais foi realizado empregando-se o método de hidrodestilação, utilizando-se aparelho de Clevenger modificado. Para tal, $75 \mathrm{~g}$ de folhas frescas de $C$. citratus e $C$. nardus foram picadas e colocadas, juntamente com água, em balão de fundo redondo com capacidade de $1 \mathrm{~L}$. O balão foi acoplado ao aparelho de Clevenger modificado e a extração foi realizada pelo período de 2,5 horas, controlando-se a temperatura a, aproximadamente, $100^{\circ} \mathrm{C}$. Posteriormente, coletou-se o hidrolato, que foi centrifugado em centrífuga de cruzeta horizontal a $965,36 \mathrm{~g}$ por 5 minutos. O óleo essencial foi retirado com auxílio de pipeta de Pasteur, colocado em frascos de vidro envoltos por papel alumínio e armazenado em geladeira a 4ํㅡ (Guimarães et al., 2008).

A partir da massa obtida na extração e da umidade do material vegetal, realizados, ambos, em três repetições, os rendimentos dos óleos essenciais extraídos foram calculados e expressos em base seca (\%v/p b.s.).

No restante do material vegetal (aproximadamente $1.775 \mathrm{~g}$ de cada espécie) 0 processo de extração dos óleos essenciais foi realizado como descrito acima. Entretanto, utilizouse balão de fundo redondo com capacidade de $4 \mathrm{~L}$.

\section{Identificação e quantificação dos constituintes químicos dos óleos essenciais}

A identificação dos constituintes dos óleos essenciais foi realizada por cromatografia em fase gasosa acoplada à espectrometria de massas (CGEM). Utilizou-se cromatógrafo a gás Shimadzu modelo CG-17A, equipado com detector seletivo de massas modelo QP5050A. Condições cromatográficas: coluna capilar de sílica fundida $(30 \mathrm{~m} \times 0,25 \mathrm{~mm} \times$ $0,25 \mu \mathrm{m}$ ) com fase ligada DB-5MS (Folsom, CA, USA); temperatura da fonte de íons de $280^{\circ} \mathrm{C}$; programação da coluna: $50^{\circ} \mathrm{C}$ por $2 \mathrm{~min}, 4^{\circ} \mathrm{C} \mathrm{min}{ }^{-1}$ até $200^{\circ} \mathrm{C}, 10^{\circ} \mathrm{C} \mathrm{min}^{-1}$ até $300^{\circ} \mathrm{C}, 300^{\circ} \mathrm{C}$ por $10 \mathrm{~min}$; gás carreador hélio ( $\left.1 \mathrm{~mL} \mathrm{~min}^{-1}\right)$; pressão inicial na coluna de 100,2 KPa; taxa de split 1:83 e volume injetado de $0,5 \mu \mathrm{L}$ ( $1 \%$ de solução em diclorometano). $\mathrm{O}$ espectrômetro de massas (EM) foi operado a 70
eV. Uma série de padrões de $n$-alcanos $\left(\mathrm{C}_{9}\right.$ a $\left.\mathrm{C}_{26}\right)$ foi injetada nas mesmas condições da amostra. Os espectros de massas obtidos foram comparados com os dados do banco de dados da biblioteca Wiley 229 e o índice de Kovats (IK), calculado para cada constituinte, foi comparado com os dados da literatura (Adams, 2001).

A quantificação dos constituintes dos óleos essenciais foi realizada utilizando-se cromatógrafo gasoso Shimadzu GC-17A, equipado com detector por ionização de chamas (DIC), nas condições operacionais: coluna capilar DB5; a programação da coluna: $50^{\circ} \mathrm{C}$ por $2 \mathrm{~min}, 4^{\circ} \mathrm{C} \mathrm{min}^{-1}$ até $200^{\circ} \mathrm{C}, 10^{\circ} \mathrm{C}$ $\mathrm{min}^{-1}$ até $300^{\circ} \mathrm{C}, 300^{\circ} \mathrm{C}$ por $10 \mathrm{~min}$; temperatura do injetor de $220^{\circ} \mathrm{C}$; temperatura de detector de $240^{\circ} \mathrm{C}$; gás carreador nitrogênio $\left(2,2 \mathrm{~mL} \mathrm{~min}{ }^{-1}\right)$; taxa de split $1: 10$ e volume injetado de $1 \mu \mathrm{L}$ ( $1 \%$ de solução em diclorometano) e pressão na coluna de $115 \mathrm{KPa}$. A quantificação de cada constituinte foi obtida por meio de normalização de áreas (\%).

\section{Determinação da atividade antibacteriana dos óleos essenciais}

O microrganismo utilizado foi $L$. monocytogenes ATCC 19117, adquirido da Seção de Coleção de Culturas da Divisão de Biologia Médica do Instituto Adolfo Lutz, em São Paulo, SP. Para a padronização do número de células, a cepa foi inicialmente inoculada em um frasco Erlenmeyer contendo $150 \mathrm{~mL}$ de meio de cultura caldo triptona de soja (TSB), o qual foi incubado a $37^{\circ} \mathrm{C}$. Em seguida, a partir do TSB, a curva de crescimento foi determinada pela realização periódica de leituras da absorbância da cultura a $600 \mathrm{~nm}$ e de diluições seriadas em solução salina $(\mathrm{NaCl} 0,9 \% \mathrm{p} / \mathrm{v}) \mathrm{com}$ posterior plaqueamento em superfície para a determinação do Log UFC $\mathrm{mL}^{-1}$, utilizando-se como meio de cultura ágar triptona de soja (TSA). Durante a realização de todo o experimento, a cepa foi estocada sob refrigeração em meio de cultura de congelamento (por $100 \mathrm{~mL}$ de água destilada: $15 \mathrm{~mL}$ de glicerol; $0,5 \mathrm{~g}$ de peptona bacteriológica; $0,3 \mathrm{~g}$ de extrato de levedura; $0,5 \mathrm{~g}$ de $\mathrm{NaCl} ; \mathrm{pH} \mathrm{7,2} \mathrm{-} \mathrm{7,4).}$ Para reativação e utilização da cepa, uma alíquota do meio de cultura de congelamento foi transferida para tubos de ensaio contendo TSB, sendo realizados dois repiques consecutivos com incubação a $37^{\circ} \mathrm{C}$, por 24 horas, neste meio de cultura. Em seguida, a cultura foi estriada em TSA vertido em placas de Petri e incubada a $37^{\circ} \mathrm{C}$, por 24 horas. Das colônias formadas na superfície do TSA, uma alçada foi retirada e transferida para frasco Erlenmeyer contendo 150 $\mathrm{mL}$ de TSB, o qual foi incubado a $37^{\circ} \mathrm{C}$, até atingir o número de células necessárias para a utilização no experimento, aproximadamente 9,17 Log UFC mL-1 $\left(O D_{600 \mathrm{~nm}}=0,895\right)$, de acordo com a curva de crescimento previamente realizada. 
Para a determinação do efeito bacteriostático, a metodologia empregada foi a de difusão em ágar, de acordo com Mendonça (2004), com modificações. Como meio de cultura, utilizou-se TSA adicionado de $0,5 \%$ de Tween 80 . Para o preparo das cavidades de deposição dos óleos essenciais, uma camada inicial do meio de cultura foi depositada em placas de Petri $(20 \times 100 \mathrm{~mm})$, sobre a qual, após a solidificação, foram dispostas pérolas de vidro. Uma sobrecamada do meio de cultura contendo o inóculo na concentração final de, aproximadamente, 8 Log UFC $\mathrm{mL}^{-1}$ foi depositada sobre as pérolas de vidro dispostas na superfície da camada inicial. A quantidade de meio de cultura utilizada na sobrecamada foi de $15 \mathrm{~mL}$, sendo $14 \mathrm{~mL}$ de TSA adicionado de $0,5 \%$ de Tween 80 e $1 \mathrm{~mL}$ de TSB contendo L. monocytogenes na concentração de, aproximadamente, 9,17 Log UFC $\mathrm{mL}^{-1}$. A adição e posterior homogeneização do TSB contendo o inóculo bacteriano ao TSA adicionado de $0,5 \%$ de Tween 80 foram realizadas quando este se encontrava na temperatura de, aproximadamente, $45^{\circ} \mathrm{C}$. Após a solidificação da sobrecamada, as pérolas de vidro foram removidas com o auxílio de pinças estéreis, dando origem às cavidades.

Em cada placa de Petri foram realizadas, no máximo, 5 cavidades. Em seguida, $10 \mu \mathrm{L}$ das diferentes concentrações $(0 ; 0,39 ; 0,78 ; 1,56 ; 3,12$; $6,25 ; 12,50 ; 25,00 ; 50,00)$ expressas em \% (v/v) dos óleos essenciais de $C$. citratus e $C$. nardus e da combinação dos dois óleos essenciais na proporção de 1:1, diluídas em etanol, foram transferidas para as cavidades. A concentração de $0 \%(\mathrm{v} / \mathrm{v})$, constituída apenas de etanol, foi utilizada como controle positivo do crescimento bacteriano. As placas foram incubadas, a $37^{\circ} \mathrm{C}$, por 24 horas e, após esse período, foram medidos os diâmetros dos halos de inibição formados, retirando-se $3 \mathrm{~mm}$ referentes ao diâmetro da cavidade. A presença de efeito bacteriostático foi caracterizada pelo comprometimento do crescimento bacteriano pela formação de halo de inibição. Amenor concentração que apresentou efeito bacteriostático foi definida como concentração mínima inibitória (CMI).

O tempo de ação bactericida foi determinado utilizando-se a CMI. Para tal, $500 \mu \mathrm{L}$ de TSB contendo L. monocytogenes na concentração de 9,17 Log UFC $\mathrm{mL}^{-1}$ foram adicionados a tubos de ensaio contendo 3 $\mathrm{mL}$ de soluções à base de óleos essenciais e solução controle, perfazendo a concentração final de, aproximadamente, 8 Log UFC mL-1. Para a elaboração das soluções à base de óleos essenciais e solução controle, foram utilizadas as proporções e os diluentes sugeridos por Chorianopoulos et al. (2008), com modificação a água destilada foi substituída por solução salina com $0,5 \%(\mathrm{v} / \mathrm{v})$ de Tween 80 . A solução salina foi utilizada no intuito de proporcionar concentração osmótica adequada à célula bacteriana, de modo que o efeito bactericida fosse atribuído somente aos óleos essenciais. O Tween 80 foi utilizado, assim como o etanol, como diluente dos óleos essenciais. Os óleos essenciais foram inicialmente diluídos em etanol e, em seguida, adicionados à solução salina $0,5 \%(\mathrm{v} / \mathrm{v})$ de Tween 80. A composição das soluções à base de óleos essenciais e a solução controle estão descritas na Tabela 1.

Foram utilizados os seguintes tempos, em minutos $0,5,10,15,20,25,30,40,50$ e 60 . Nesses períodos, alíquotas de $100 \mu \mathrm{L}$ das soluções contendo o inóculo bacteriano foram retiradas e plaqueadas na superfície do TSA. O inóculo foi espalhado, com alça de drigalski, até a completa absorção pelo meio de cultura. Em seguida, as placas de Petri contendo TSA foram incubadas a $37^{\circ} \mathrm{C}$, por 24 horas. Foram realizadas três repetições em duplicata. $O$ tempo de ação bactericida foi definido como o primeiro tempo, em minutos, que apresentou ausência total de crescimento bacteriano, representado pela formação de colônias, na superfície do TSA.

\section{estatística \\ Delineamento experimental e análise}

O delineamento experimental utilizado foi o inteiramente casualizado (DIC) em esquema fatorial

TABELA 1. Composição das soluções à base de óleos essenciais e solução controle utilizadas na determinação do tempo de ação bactericida.

\begin{tabular}{cccc}
\hline & \multicolumn{3}{c}{ Composição (\%) } \\
\cline { 2 - 4 } Soluções & $\begin{array}{c}\text { Óleo } \\
\text { essencial }\end{array}$ & Etanol & $\begin{array}{c}\text { Solução salina com } \\
\mathbf{0 , 5 \%}(\mathbf{v} / \mathbf{v}) \text { de Tween 80 }\end{array}$ \\
\hline C. nardus & 3,12 & 16,88 & 80,00 \\
C. citratus & 1,56 & 18,44 & 80,00 \\
$\begin{array}{c}\text { Combinação } \\
(1: 1)\end{array}$ & 1,56 & 18,44 & 80,00 \\
Controle & 0,00 & 20,00 & 80,00 \\
\hline
\end{tabular}

Rev. Bras. Pl. Med., Botucatu, v.13, n.1, p.8-16, 2011. 
$3 \times 9$ (óleos essenciais e a combinação $x$ concentrações), com três repetições. Os dados foram submetidos à análise de variância e as médias comparadas pelo teste de Tukey, a $5 \%$ de probabilidade, e análise de regressão. As análises estatísticas foram realizadas utilizando-se o programa Sisvar versão 4.6 (Ferreira, 2003).

\section{RESULTADO E DISCUSSÃO}

As folhas frescas de $C$. citratus e $C$. nardus apresentaram 71,66 $\pm 2,88$ e 67,33 $\pm 1,15 \%$ (v/p) de umidade, respectivamente. Já o rendimento dos óleos essenciais, em base seca (b.s.), foi de 1,39 $\pm 0,54 \%$ ( $v /$ p) para $C$. citratus e $2,27 \pm 0,70 \%(\mathrm{v} / \mathrm{p})$ para $C$. nardus. Em ambos os casos os resultados foram expressos pela média de três repetições \pm 0 desvio padrão.

Resultados diferentes dos obtidos, no que diz respeito ao rendimento de óleo essencial de $C$. citratus e de $C$. nardus, foram encontrados em vários trabalhos consultados. Pereira et al. (2008), estudando o rendimento de óleo essencial de $C$. citratus, obtiveram o valor de 2,16\%, em base seca (b.s.). No que diz respeito ao óleo essencial de $C$. nardus, Marco et al. (2007), estudando diferentes espaçamentos, alturas e épocas de cortes, encontraram resultados variando de $3,52 \%$ a $4,18 \%$ de óleo essencial na matéria seca. Segundo Burt (2004), variações no rendimento de óleo essencial entre plantas pertencentes à mesma espécie podem ser atribuídas, principalmente, a diferenças de época de colheita, tipo de solo, clima da região e umidade relativa do ar.

Em relação à composição química, observase, pelos dados das Tabelas 2 e 3, que os óleos essenciais de $C$. citratus e $C$. nardus apresentaram monoterpenos como constituintes majoritários. No óleo essencial de $C$. citratus, o componente majoritário encontrado foi o geranial $(42,92 \%)$, seguido do neral $(30,91 \%)$. Estes dois compostos são estereoisômeros e a mistura constitui o citral. Assim, o citral é uma mistura isomérica de geranial [(2E)3,7-dimetilocta-2,6-dienal; citral $A$ ou isômero $E]$ e neral [(2Z)-3,7-dimetilocta-2,6-dienal; citral B ou isômero Z] (El Fattah et al., 1992). No óleo essencial de $C$. nardus, os constituintes majoritários encontrados foram citronelal $(34,61 \%)$, seguido de geraniol $(23,18 \%)$ e citronelol $(12,10 \%)$. A maior concentração de citronelal ocorreu, provavelmente, devido à oxidação do citronelol, um álcool secundário, em citronelal.

Em óleos essenciais, os constituintes e as concentrações relativas não dependem somente da espécie da planta. Entre os vários fatores que influenciam a composição química, os mais importantes são a origem da planta, a parte da planta utilizada, o estágio de desenvolvimento da planta, as
TABELA2. Constituintes químicos do óleo essencial de Cymbopogon citratus identificados por CG-EM e os respectivos teores.

\begin{tabular}{ccc}
\hline Constituintes & IK calculado & Teor (\%) \\
\hline Mirceno & 991 & 1,37 \\
(Z)- $\beta$-ocimeno & 1040 & 0,14 \\
(E)- $\beta$-ocimeno & 1051 & 0,20 \\
Linalol & 1199 & 1,52 \\
Neral & 1244 & 30,91 \\
Geraniol & 1254 & 1,18 \\
Geranial & 1273 & 42,92 \\
2-undecanona & 1292 & 4,13 \\
Outros & - & 17,63 \\
\hline Total & & $\mathbf{1 0 0 , 0 0}$ \\
\hline
\end{tabular}

TABELA 3. Constituintes químicos do óleo essencial de Cymbopogon nardus identificados por CG-EM e seus respectivos teores.

\begin{tabular}{lcc}
\hline \multicolumn{1}{c}{ Constituintes } & $\begin{array}{c}\text { IK } \\
\text { calculado }\end{array}$ & $\begin{array}{c}\text { Teor } \\
(\%)\end{array}$ \\
\hline Limoneno & 1028 & 1,09 \\
Linalol & 1100 & 0,51 \\
Neo-isopulegol & 1147 & 0,25 \\
Citronelal & 1156 & 34,61 \\
Citronelol & 1229 & 12,10 \\
Geraniol & 1254 & 23,18 \\
Geranial & 1268 & 0,57 \\
Acetato de citronelil & 1350 & 2,06 \\
$\beta$-elemeno & 1389 & 3,28 \\
Germacreno D & 1481 & 1,78 \\
a-muuroleno & 1497 & 1,11 \\
Y-cadineno & 1512 & 2,94 \\
$\delta$-cadineno & 1517 & 2,63 \\
Outros & - & 13,89 \\
Total & & $\mathbf{1 0 0 , 0 0}$ \\
\hline
\end{tabular}

condições climáticas e de crescimento, como temperatura, solo e adubação e as condições de destilação e estocagem (Oladimeji et al., 2001). Tais fatores podem explicar as diferenças observadas entre as composições químicas dos óleos essenciais 
utilizados neste estudo (Tabelas 2 e 3 ) e as composições químicas dos óleos essenciais de outros trabalhos já publicados. Guimarães et al. (2008), por exemplo, analisando a composição química do óleo essencial de $C$. citratus, encontraram como constituintes o geranial $(37,42 \%)$, neral $(31,89 \%)$, mirceno $(23,77 \%)$, linalol $(0,82 \%),(Z)-\beta$ ocimeno $(0,50 \%)$, (E)- $\beta$-ocimeno $(0,28 \%)$ e 2 undecanona (0,27\%). Já Castro et al. (2007) obtiveram como principais constituintes, para o óleo essencial de $C$. nardus, citronelal (36,67\%), geraniol $(25,05 \%)$, citronelol $(11,40 \%)$ e elemol $(6,99 \%)$. Contudo, observa-se que os constituintes majoritários encontrados neste estudo se assemelham aos relatados por Castro et al. (2007) e Guimarães et al. (2008).

O grau de inibição do crescimento microbiano por óleos essenciais pode ser estimado pela metodologia de difusão em ágar. O potencial de determinado óleo essencial é representado pelo tamanho da zona de inibição formada na superfície do ágar, em volta do disco ou da cavidade (Kalemba \& Kunicka, 2003). Todavia, apesar da metodologia ser amplamente utilizada (Mondello et al., 2003), ela é criticada por alguns autores, pois acredita-se que a natureza hidrofóbica dos óleos essenciais impede a difusão uniforme dessas substâncias através do meio de cultura (Lambert et al., 2001). Entretanto, Inouye et al. (2006) demonstraram que a atividade de vapor dos óleos essenciais contribui na formação do halo de inibição, o que sugere que a difusão em ágar é método válido na determinação da atividade antimicrobiana, no qual a baixa capacidade de difusão dos óleos essenciais é compensada pela elevada volatilidade dos mesmos.

A capacidade dos óleos essenciais de inibir o crescimento bacteriano permite que os mesmos sejam utilizados como antimicrobianos naturais na indústria de alimentos. Neste contexto, é necessário verificar em qual concentração os mesmos devem ser aplicados. Para isso, devem ser realizados testes in vitro que determinem a menor concentração que apresente efeito bacteriostático ou inibitório. Dessa forma, a concentração mínima inibitória (CMI) é citada como medida do desempenho antibacteriano dos óleos essenciais (Burt, 2004). As concentrações mínimas inibitórias (CMIs) encontradas foram de $1,56 \%$ (v/v), para o óleo essencial de $C$. citratus e para a combinação dos óleos essenciais de $C$. citratus e $C$. nardus, e $3,12 \%(\mathrm{v} / \mathrm{v})$, para o óleo essencial de $C$. nardus.

Oussalah et al. (2007) também observaram superioridade na atividade antibacteriana do óleo essencial de $C$. citratus frente a $L$. monocytogenes, quando comparado ao de $C$. nardus. ACMI encontrada para o óleo essencial de $C$. citratus foi $0,4 \%(\mathrm{v} / \mathrm{v})$, enquanto, para o óleo essencial de $C$. nardus, foi $0,8 \%$ $(\mathrm{v} / \mathrm{v})$. Os menores valores encontrados por estes autores, em comparação aos obtidos neste estudo, podem ser atribuídos às menores concentrações de

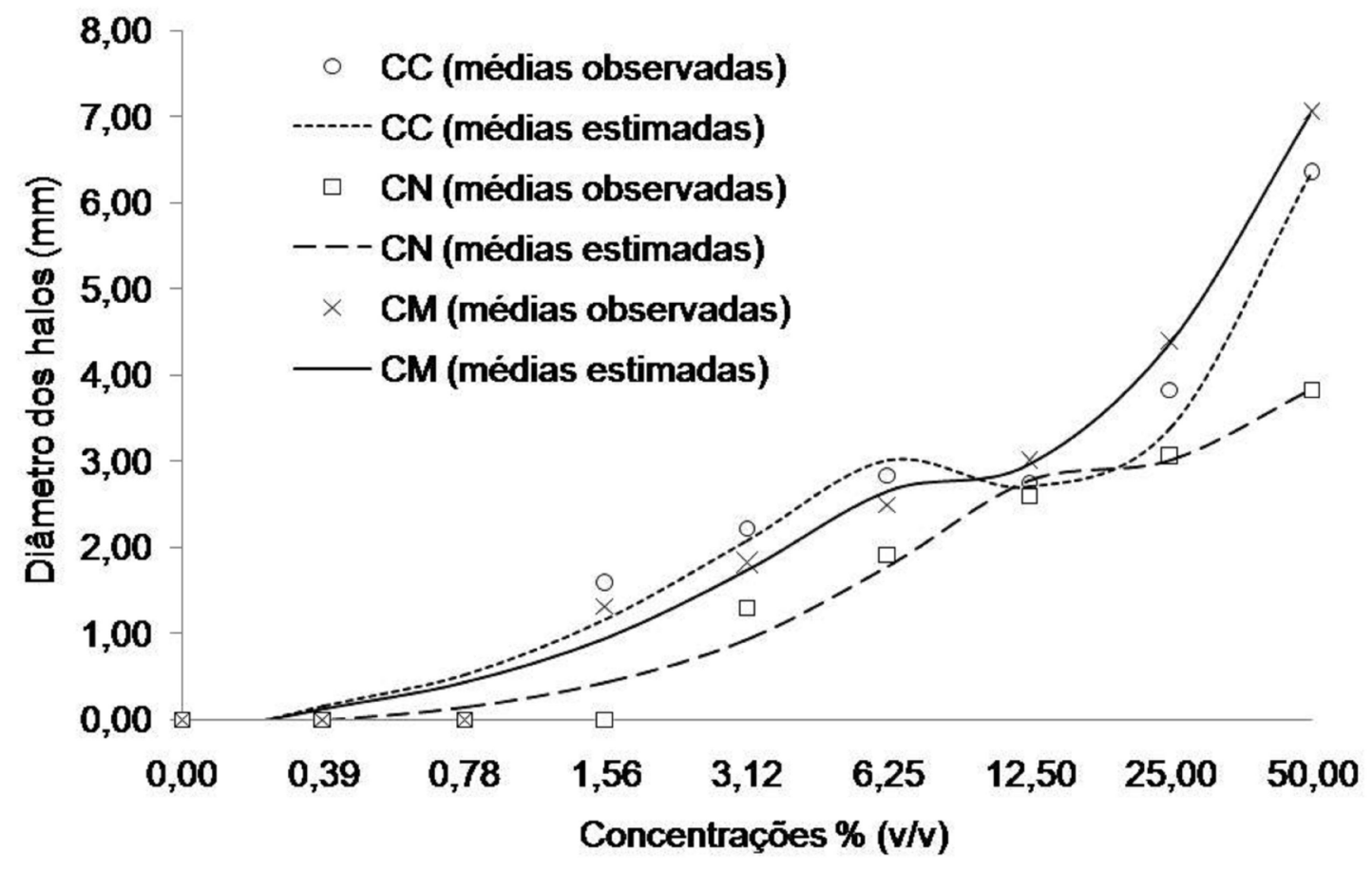

FIGURA 1. Diâmetro médio dos halos de inibição, formados em função das diferentes concentrações dos óleos essenciais de Cymbopogon citratus (CC), Cymbopogon nardus (CN) e a combinação (CM), frente a Listeria monocytogenes. 
inóculo bacteriano utilizadas pelos mesmos, cerca de 4 e 5 Log UFC $\mathrm{mL}^{-1}$.

Apesar de os óleos essenciais de $C$. citratus e $C$. nardus e sua combinação apresentarem efeito bacteriostático frente a $L$. monocytogenes na maioria das concentrações, observou-se que a efetividade dos mesmos depende da concentração em que são utilizados. $\mathrm{Na}$ análise de variância realizada a partir dos resultados obtidos pelo método de difusão em ágar, observou-se interação significativa $(p<0,01)$ entre os óleos essenciais e as diferentes concentrações utilizadas. Dessa forma, procedeu-se ao desdobramento de concentrações dentro de cada nível de óleo essencial (Figura 1) e de óleos essenciais dentro de cada nível de concentração (Tabela 4).

A Figura 1 ilustra o comportamento do diâmetro dos halos de inibição formados frente às diferentes concentrações de óleos essenciais utilizadas. Nota-se, que a partir das CMls houve aumento do diâmetro dos halos de inibição com o aumento da concentração dos óleos essenciais, com exceção da concentração de $12,50 \%$ (v/v) do óleo essencial de $C$. citratus, onde se observa discreta redução.

Pelos dados da Tabela 4, observa-se que nas concentrações de 12,50,6,25, 3,12, 0,39, 0,78 e $0,00 \%(\mathrm{v} / \mathrm{v})$, os efeitos bacteriostáticos dos óleos essenciais e sua combinação não diferiram entre si ( $p>0,05$ ). Já nas concentrações de 50,00 e 1,56\% (v/ $v)$, os efeitos bacteriostáticos do óleo essencial de C. citratus e da combinação dos óleos essenciais de C. citratus e $C$. nardus não diferiram entre $\mathrm{si}(\mathrm{p}>0,05)$, entretanto, foram superiores $(p<0,05)$ ao do óleo essencial de $C$. nardus.

Diferenças na atividade antibacteriana existentes entre óleos essenciais de diferentes espécies de plantas, como a observada entre os óleos essenciais de $C$. citratus e $C$. nardus, são relacionadas à concentração e à natureza de seus constituintes químicos (Chang et al., 2001). Segundo Kalemba \& Kunicka (2003), aldeídos possuem maior atividade antimicrobiana quando comparados a alcoóis. Em relação aos óleos essenciais utilizados, os constituintes majoritários de $C$. citratus foram aldeídos monoterpênicos (neral e geranial que isomericamente formam o citral), no caso de $C$. nardus foi um aldeído (citronelal) e dois alcoóis (geraniol e citronelol) (Tabelas 2 e 3 ). Dessa forma, a superioridade do efeito bacteriostático apresentado pelo óleo essencial de $C$. citratus nas concentrações de 50,00 e 1,56\% (v/v), quando comparado ao óleo essencial de $C$. nardus, pode ser explicada pelo elevado teor de citral $(73,83 \%)$ presente em sua composição (Tabela 2). A maior proporção de aldeídos também pode ter sido responsável pela superioridade do efeito bacteriostático da combinação dos óleos essenciais nestas mesmas concentrações, quando comparado ao do óleo essencial de $C$. nardus utilizado puro.

O mecanismo de ação dos monoterpenos envolve, principalmente, efeitos tóxicos à estrutura e à função da membrana celular. Como resultado do caráter lipofílico, os monoterpenos irão, preferencialmente, se deslocar da fase aquosa em direção às estruturas de membrana (Sikkema et al., 1995). O acúmulo dos constituintes dos óleos essenciais na bicamada lipídica da membrana citoplasmática irá conferir a esta uma característica de permeabilidade. Em bactérias, a permeabilização

TABELA 4. Diâmetro médio dos halos de inibição, formados em função das diferentes concentrações dos óleos essenciais de Cymbopogon nardus, Cymbopogon citratus e a combinação, frente a Listeria monocytogenes.

\begin{tabular}{cccc}
\hline $\begin{array}{c}\text { Concentrações } \\
\%(\mathbf{v} / \mathbf{v})\end{array}$ & C. nardus & C. citratus & Combinação \\
\cline { 2 - 4 } & $0,00 \pm 0,00^{\mathrm{a}}$ & $0,00 \pm 0,00^{\mathrm{a}}$ & $0,00 \pm 0,00^{\mathrm{a}}$ \\
0,00 & $0,00 \pm 0,00^{\mathrm{a}}$ & $0,00 \pm 0,00^{\mathrm{a}}$ & $0,00 \pm 0,00^{\mathrm{a}}$ \\
0,39 & $0,00 \pm 0,00^{\mathrm{a}}$ & $0,00 \pm 0,00^{\mathrm{a}}$ & $0,00 \pm 0,00^{\mathrm{a}}$ \\
0,78 & $0,00 \pm 0,00^{\mathrm{a}}$ & $1,58 \pm 0,14^{\mathrm{b}}$ & $1,32 \pm 0,32^{\mathrm{b}}$ \\
1,56 & $1,30 \pm 0,20^{\mathrm{a}}$ & $2,22 \pm 0,26^{\mathrm{a}}$ & $1,83 \pm 0,38^{\mathrm{a}}$ \\
3,12 & $1,92 \pm 0,33^{\mathrm{a}}$ & $2,83 \pm 0,38^{\mathrm{a}}$ & $2,50 \pm 0,50^{\mathrm{a}}$ \\
6,25 & $2,60 \pm 0,36^{\mathrm{a}}$ & $2,75 \pm 0,75^{\mathrm{a}}$ & $3,00 \pm 0,25^{\mathrm{a}}$ \\
12,50 & $3,05 \pm 0,26^{\mathrm{a}}$ & $3,38 \pm 1,79^{\mathrm{a}}$ & $4,38 \pm 0,13^{\mathrm{b}}$ \\
25,00 & $3,83 \pm 1,13^{\mathrm{a}}$ & $6,35 \pm 0,41^{\mathrm{b}}$ & $7,05 \pm 0,69^{\mathrm{b}}$ \\
50,00 &
\end{tabular}

Resultados expressos pela média dos diâmetros dos halos de inibição em milímetros $(\mathrm{mm}) \pm 0$ desvio padrão. Médias seguidas da mesma letra nas linhas não diferem entre si, pelo teste de Tukey, a $5 \%$ de probabilidade (diferença mínima significativa $=0,98)$. 
da membrana citoplasmática está associada à dissipação da força próton motiva, no que diz respeito à redução do poo/de ATP, do pH interno e do potencial elétrico, e à perda de íons, como íons potássio e fosfato (Bakkali et al., 2008). Dessa forma, danos estruturais à membrana citoplasmática levam ao comprometimento de suas funções como barreira seletiva e local de ação enzimática e geração de energia (Sikkema et al., 1994).

Os diâmetros dos halos de inibição formados pela combinação dos óleos essenciais nas concentrações de 50,00, 25,00 e 12,50\% (v/v) apresentaram-se superiores aos diâmetros dos halos de inibição dos óleos essenciais puros nas mesmas concentrações. Porém, o efeito sinergístico pode ser observado somente na concentração de $25,00 \%$ (v/ v), na qual o efeito bacteriostático da combinação dos óleos essenciais foi significativamente superior $(p<0,05)$ ao dos mesmos utilizados puros (Tabela 4).

A combinação de óleos essenciais de diferentes espécies de plantas pode representar alternativa para potencializar a ação dos mesmos (Pereira et al., 2008). O termo sinergismo é definido como o aumento da atividade de compostos ou fatores quando aplicados em conjunto, comparada à atividade dos mesmos, quando utilizados individualmente (Williamson, 2001; Ceylan \& Fung, 2004). Tratandose de óleos essenciais, vários estudos já realizados in vitro, utilizando a combinação de óleos essenciais de diferentes espécies de plantas, alcançaram resultados promissores (Delaquis et al., 2002; Fu et al., 2007; Al-Bayati, 2008; Gutierrez et al., 2008), o que demonstra que esta é uma alternativa viável a ser utilizada no controle microbiológico de alimentos.

O método de difusão em ágar comprovou o potencial bacteriostático da maioria das concentrações dos óleos essenciais de $C$. citratus e C. nardus, puros e em combinação. Todavia, para que estes sejam totalmente efetivos na eliminação de L. monocytogenes, a comprovação do efeito bactericida é necessária. Com esse intuito, as CMls encontradas foram utilizadas na determinação do tempo de ação bactericida. Todas as soluções à base de óleos essenciais utilizadas (Tabela 1) apresentaram atividade bactericida. Entretanto, os tempos de ação bactericida obtidos diferiram entre si, sendo de 0 minuto para a solução à base de óleo essencial de C. nardus, 5 minutos para a solução à base de óleo essencial de $C$. citratus e 15 minutos para a solução constituída da combinação dos óleos essenciais. $\mathrm{Na}$ solução controle, o inóculo bacteriano manteve-se viável durante todo o período analisado (60 minutos). Este resultado indica que os tempos de ação bactericida obtidos podem estar diretamente relacionados às quantidades de óleos essenciais utilizadas nas soluções, uma vez que quanto maior a quantidade de óleo essencial, menor o tempo de ação bactericida encontrado. Segundo Holley \& Patel (2005), mudanças na concentração dos óleos essenciais podem alterar a natureza da ação antibacteriana e este efeito pode estar relacionado à influência da concentração em relação à capacidade de solubilidade na membrana citoplasmática. Dessa forma, quanto maior a concentração de óleo essencial utilizada na solução, maior será a capacidade do mesmo de se deslocar em direção à membrana citoplasmática bacteriana, afetando assim seu funcionamento.

Diante dos resultados obtidos, verifica-se que os óleos essenciais de $C$. citratus e $C$. nardus constituem novas alternativas de antibacterianos naturais a serem utilizados no controle de $L$. monocytogenes na indústria de alimentos. O efeito sinergístico da combinação dos mesmos não deve ser descartado e representa uma maneira de potencializar a atividade antibacteriana individual desses compostos.

\section{AGRADECIMENTO}

Ao Conselho Nacional de Desenvolvimento Científico e Tecnológico (CNPq) pela bolsa de estudos da primeira autora, que possibilitou a realização do Mestrado. AFundação de Apoio a Pesquisa do Estado de Minas Gerais (FAPEMIG) pelo suporte financeiro.

\section{REFERÊNCIA}

ADAMS, R.P. Identification of essential oils components by gas chromatography/mass spectroscopy. Carol Stream: Allured, 2001. 456p.

AL-BAYATI, F.A. Synergistic antibacterial activity between Thymus vulgaris and Pimpinella anisum essential oils and methanol extracts. Journal of Ethnopharmacology, v.116, n.3, p.403-6, 2008.

BAKKALI, F. et al. Biological effects of essential oils: a review. Food and Chemical Toxicology, v.46, n.2, p.44675, 2008.

BURT, S. Essential oils: their antibacterial properties and potential applications in foods: a review. International Journal of Food Microbiology, v.94, n.3, p.223-53, 2004. CASTRO, H.G. et al. Crescimento, teor e composição do óleo essencial de Cymbopogon nardus (L.). Revista Brasileira de Plantas Medicinais, v.9, n.4, p.55-61, 2007. CASTRO, L.O.; RAMOS, R.L.D. Principais gramíneas produtoras de óleos essenciais: Cymbopogon citratus (DC.) Stapf., capim-cidró, Cymbopogon martinii (Rox.) J.F. Watson, palma-rosa, Cymbopogon nardus (L.) Rendle, citronela, Elyonurus candidus (Trin.) Hack. , capim-limão, Vetiveria zizanioides (L.) Nash, vetiver. Porto Alegre: FEPAGRO, 2003. 23p.

CAVA, R. et al. Antimicrobial activity of clove and cinnamon essential oils against Listeria monocytogenes in pasteurized milk. Journal of Food Protection, v.70, n.12, p.2757-63, 2007.

CEYLAN, E.; FUNG, D.Y.C. Antimicrobial activity of spices. 
Journal of Rapid Methods and Automation in Microbiology, v.12, n.1, p.1-55, 2004.

CHANG, S.T.; CHEN, P.F.; CHANG, S.C. Antibacterial activity of leaf essential oils and their constituents from Cinnamomum osmophloeum. Journal of Ethnopharmacology, v.77, n.1, p.123-7, 2001.

CHORIANOPOULOS, N.G. et al. Disinfectant test against monoculture and mixed-culture biofilms composed of technological, spoilage and pathogenic bacteria: bactericidal effect of essential oil and hydrosol of Satureja thymbra and comparison with standard acid-base sanitizers. Journal of Applied Microbiology, v.104, n.6, p.1586-96, 2008.

DANTAS, A.A.A.; CARVALHO, L.G.D.; FERREIRA, E. Classificação e tendências climáticas em Lavras, MG. Ciência e Agrotecnologia, v.31, n.6, p.1862-6, 2007.

DELAQUIS, P.J. et al. Antimicrobial activity of individual and mixed fractions of dill, cilantro, coriander and eucalyptus essential oils. International Journal of Food Microbiology, v.74, n.1/2, p.101-9, 2002.

EL FATTAH, M.A. et al. Effect of drying on the physicochemical properties and chemposition of lemongrass oil. Menofiya Journal Agriculture Research, v.17, n.3, p.1211-30, 1992.

FERREIRA, D.F. SISVAR - Sistema de análise de variância para dados balanceados: programa de análises estatísticas e planejamento de experimentos Versão 4.6. Lavras: DEX/UFLA, 2003. Software.

FU, Y.J. et al. Antimicrobial activity of clove and rosemary essential oils alone and in combination. Phytotherapy Research, v.21, n.10, p.989-94, 2007.

GIULIETTI, A.M. et al. Biodiversidade e conservação das plantas no Brasil. Megadiversidade, v.1, n.1, p.52-61, 2005. GUIMARÃES, L.G.L. et al. Influência da luz e da temperatura sobre a oxidação do óleo essencial de capim-limão (Cymbopogon citratus (DC.) Stapf). Química Nova, v.31, n.6, p.1476-80, 2008.

GUTIERREZ, J.; BARRY-RYAN, C.; BOURKE, P. The antimicrobial efficacy of plant essential oil combinations and interactions with food ingredients. International Journal of Food Microbiology, v.124, n.1, p.91-7, 2008. HOLLEY, R.A.; PATEL, D. Improvement in shelf-life and safety of perishable foods by plant essential oils and smoke antimicrobials. Food Microbiology, v.22, n.4, p.273-92, 2005.

INOUYE, S. et al. A novel method to estimate the contribution of the vapor activity of essential oils in agar diffusion assay. Japanese Journal of Medical Mycology, v.27, n.2, p.91-8, 2006.

KALEMBA, D.; KUNICKA, A. Antibacterial and antifungal properties of essential oils. Current Medicinal Chemistry, v.10, n.10, p.813-29, 2003.

KELSEY, R.G.; REYNOLDS, G.W.; RODRIGUEZ, E. The chemistry of. biologically active constituents secreted and stored in plant glandular trichomes. In: RODRIGUEZ, E.; HEALEY, P.L.; METHA, I. (Eds.). Biology and chemistry of plant trichomes. New York: Plenum, 1984. p.187-241. LAMBERT, R.J.W. et al. A study of the minimum inhibitory concentration and mode of action of oregano essential oil, thymol and carvacrol. Journal of Applied Microbiology, v.91, n.3, p.453-62, 2001.

LEBERT, I.; LEROY, S.; TALON, R. Effect of industrial and natural biocides on spoilage, pathogenic and technological strains grown in biofilm. Food Microbiology, v.24, n.3, p.281-7, 2007.

LORENZI, H.; MATOS, F.J.A. Plantas medicinais no Brasil: nativas e exóticas cultivadas. Nova Odessa: Plantarum, 2002. 544p.

MARCO, C.A. et al. Características do óleo essencial de capim-citronela em função de espaçamento, altura e época de corte. Horticultura Brasileira, v.25, n.3, p.42932, 2007.

MARTINAZZO, A. P. et al. Análise e descrição matemática da cinética de secagem de folhas de capim-limão. Revista Brasileira de Engenharia Agrícola e Ambiental, v.11, n.3, p.301-6, 2007.

MENDONÇA, A.T. Efeito dos óleos essenciais de condimentos sobre o crescimento de Staphylococcus aureus em ricota cremosa. 2004. 72p. Tese (Doutorado em Ciência dos Alimentos) - Universidade Federal de Lavras, Lavras.

MING, L.C. et al. Yield of essential oil and citral content in different parts of lemongrass leaves (Cymbopogon citratus (DC.) Stapf - Poaceae. Acta Horticulturae, v.426, n.1, p.555-9, 1996.

MONDELLO, F. et al. In vitro and in vivo activity of tea tree oil against azole- susceptible and resistant human pathogenic yeasts. Journal of Antimicrobial Chemotherapy, v.51, n.5, p.1223-9, 2003.

OLADIMEJI, F.A. et al. Effect of autoxidation on the composition and antimicrobial activity of essential oil of Lippia multiflora. Pharmaceutical and Pharmacological Letters, v.11, n.2, p.64-7, 2001.

OUSSALAH, M. et al. Inhibitory effects of selected plant essential oils on the growth of four pathogenic bacteria: E. coliO157:H7, Salmonella Typhimurium, Staphylococcus aureus and Listeria monocytogenes. Food Control, v.18, n.5, p.414-20, 2007.

PEREIRA, A.A. et al. Caracterização química e efeito inibitório de óleos essenciais sobre o crescimento de Staphylococcus aureus e Escherichia coli. Ciência e Agrotecnologia, v.32, n.3, p.887-93, 2008.

PIMENTEL, F.A. et al. A convenient method for the determination of moisture in aromatic plants. Química Nova, v.29, n.2, p.373-5, 2006.

ROCOURT, J.; JACQUET, C.; REILLY, A. Epidemiology of human listeriosis and seafoods. International Journal of Food Microbiology, v.62, n.3, p.197-209, 2000.

SIANI, A.C. et al. Óleos essenciais: potencial antiinflamatório. Biotecnologia, Ciência e Desenvolvimento, v.16, p.38-43, 2000.

SIKKEMA, J.; BONT, J.A.M.; POOLMAN, B. Interactions of cyclic hydrocarbons with biological membranes. Journal of Biological Chemistry, v.269, n.11, p.8022-8, 1994.

SIKKEMA, J.; BONT, J.A.M.; POOLMAN, B. Mechanisms of membrane toxicity of hydrocarbons. Microbiological Reviews, v.59, n.2, p.201-22, 1995.

SOLOMAKOS, N. et al. The antimicrobial effect of thyme essential oil, nisin, and their combination against Listeria monocytogenes in minced beef during refrigerated storage. Food Microbiology, v.25, n.1, p.120-7, 2008.

ULTEE, A.; KETS, E.P.; SMID, E.J. Mechanisms of action of carvacrol on the food-borne pathogen Bacillus cereus. Applied and Environmental Microbiology, v.65, n.10, p.4606-10, 1999.

WILLIAMSON, E.M. Synergy and other interactions in phytomedicines. Phytomedicine, v.8, n.5, p.401-9, 2001. 